\title{
DAMPAK APLIKASI INSEKTISIDA PERMETRIN TERHADAP SERANGGA HAMA (THOSEA SP.) DAN SERANGGA PENYERBUK (ELAEIDOBIUS KAMERUNICUS) DALAM AGROEKOSISTEM KELAPA SAWIT
}

\author{
Rosma Hasibuan $^{1}$, I Gede Swibawa ${ }^{1}$, Agus M. Hariri ${ }^{1}$, Sudi Pramono ${ }^{1}$, F.X. Susilo ${ }^{1}$, \\ dan Nurafiah Karmike².
}

\begin{abstract}
Impact of Permethrin-Insecticide Application on Insect Pest (Thosea sp.) and Insect Pollinators (Elaeidobius kamerunicus) in Oil Palm Agroecosystem. Insecticide efficacy studies are usually determined from the target insect (pest) data without regard to the effect of that treatment on the non-target insects (such as pollinators). This study examined the effect of permethrin (one of widely used insecticides for agriculture) on defoliating insect pest (nettle caterpillar, Thosea sp.) and insect pollinator (weevil, Elaeidobius kamerunicus) which lives on pollen of male oil palm flowers. A complete block design was used in which each of four blocks consisted of 5 treatments (4 concentrations of permethrin; 50; 100; 200; and $250 \mathrm{ppm}$ and control). The results clearly demonstrated that the application of permethrin reduced significantly the number of nettle caterpillar throughout all sprayed plants (up to $100 \% 14 \mathrm{~d}$ after treatments). A significant difference in mean population of the caterpillar were detected between plots sprayed with permethrin $(0.05 ; 0.25 ; 0.53$; and 2.00 larvae/leaves at concentrations of 250; 200; 100; and 50 ppm respectively) and control plant (5.2 larvae/leaves) $3 \mathrm{~d}$ after treatments. This insecticide effects persisted for at least $14 \mathrm{~d}$ after treatments. On the other hand, permethrin application in oil palm agroecosystem had adverse effects on main pollinator (E. kamerunicus). The number of weevil pollinators on sprayed plants (12.5; 59.3; 77.5; and 209.5 weevil/male flower at concentrations of 50; 100; 200; and $250 \mathrm{ppm}$ respectively) were significantly fewer compared to the control plants (976.0 weevil/male flower). The results indicate that, despite high efficacy of permethrin in reducing number of insect pests of oil palm (Thosea sp.), its application also cause a severe impact on important insect pollinators (E. kamerunicus).
\end{abstract}

Kata kunci: Thosea sp., ulat api, Elaeidobius kamerunicus, serangga penyerbuk, kelapa sawit, insektisida permetrin

\section{PENDAHULUAN}

Perkebunan kelapa sawit (Elaeis guineensis Jacq.) di Indonesia terus berkembang dan tidak hanya monopoli perkebunan besar negara atau swasta tetapi juga perkebunan rakyat. Permintaan akan minyak sawit dalam maupun luar negeri mendorong pengusaha perkebunan untuk melakukan pemeliharaan yang intensif pada pertanaman kelapa sawit (Risza, 1994). Data BPS (2000) menunjukkan bahwa luas areal kelapa sawit di Propinsi Lampung mencapai 58.086 ha dengan produksi 99.621 ton.

Salah satu hama penting tanaman kelapa sawit adalah ulat api Thosea sp. (Lepidoptera: Limacodidae) yang merupakan hama pemakan daun. Pada tingkat serangan tinggi, hama ini dapat mengakibatkan tanaman kelapa sawit menjadi gundul dan yang tertinggal adalah hanya tulang daun. Kejadian ini menimbulkan kegagalan panen yang mengakibatkan kerugian besar pada perusahaan perkebunan kelapa sawit. (Kalshoven, 1981; Risza, 1994; Sipayung, 1987).

Teknik pengendalian yang banyak dilakukan adalah dengan penyemprotan insektisida. Tingginya penggunaan insektisida disebabkan oleh berbagai faktor seperti: (1) dapat mengendalikan populasi hama secara cepat dan efektif, (2) selalu tersedia di pasaran, (3) dan aplikasinya relatif mudah.

Sementara itu, pemahaman tentang dampak berbahaya insektisida terhadap lingkungan dan organisme non-target masih kurang memadai. Salah satu serangga non-target yang mempunyai peranan penting dalam budidaya tanaman kelapa sawit adalah kumbang penyerbuk Elaeidobius kamerunicus (Coleoptera: Curculionidae). Kumbang moncong (weevil) ini berukuran kecil (panjang $\pm 4 \mathrm{~mm}$ dan lebar \pm 1,5 dan berwarna cokat kehitaman (Syed, 1986 dan 1987; Syed et al., 1982; Wahid et al., 1987; Yee et al., 1985). Serangga penyerbuk yang didatangkan dari negara Kamerun (Afrika) pada tahun 1983,.

\footnotetext{
${ }^{1}$ Dosen Jurusan Proteksi Tanaman, Fakultas Pertanian Universitas Lampung

${ }^{2}$ Alumnus Jurusan Proteksi Tanaman, Fakultas Pertanian Universitas Lampung
} 
dilepas pertama kali pada kebun percobaan kelapa sawit Sungai Pancur, Sumatera Utara. Sejak saat itu, serangga penyerbuk ini sangat berperan dalam proses penyerbukan tanaman kelapa sawit di seluruh Indonesia termasuk perkebunan PTP Nusantara VII Bekri, Lampung Tengah. Sebelum kumbang penyerbuk ini didatangkan, penyerbukan tanaman kelapa sawit dilakukan dengan tangan manusia, yang tentu menambah ongkos produksi.

Penelitian ini bertujuan untuk menyelidiki dampak aplikasi insektisida permetrin terhadap populasi ulat api Thosea sp. dan kumbang penyerbuk E. kamerunicus pada tanaman kelapa sawit.

\section{METODE PENELITIAN}

Penelitian dilaksanakan di perkebunan kelapa sawit milik PT Perkebunan Nusantara VII Unit Usaha Bekri, di Kecamatan Gunung Sugih, Lampung Tengah. Perkebunan Bekri mempunyai areal perkebunan seluas 3.622 ha yang terdiri atas 4 afdeling. Lokasi pengujian yang dipilih adalah Afdeling I yang memiliki luas 738 ha. Percobaan pengujian dilaksanakan pada areal tanaman kelapa sawit berumur 4 tahun (tahun tanam 1998) dan sudah mulai berproduksi (berbuah) dengan luas kurang lebih 1.0 ha. Percobaan berlangsung mulai bulan Januari hingga April 2002.

Tanaman terok yang ditetapkan adalah tanaman kelapa sawit yang terserang oleh larva Thosea sp. (populasi minimum 8 larva/pelepah) dengan sebaran di antara seluruh petak percobaan lebih kurang merata. Satuan petak percobaan terdiri dari 4 (empat) pohon. Dari setiap pohon diambil 4 (empat) pelepah secara sistematis (mewakili pelepah daun bagian atas, tengah, dan bawah). Setiap petak percobaan (4 pohon) dipisahkan oleh 2 (dua) baris pohon kelapa sawit. Setiap kelompok ditandai dengan tiang/papan label dan setiap tanaman terok yang telah ditentukan diberi tanda dengan cat warna merah pada sebagian pelepahnya serta diberi label seng berukuran 15 x $10 \mathrm{~cm}$. Semua perlakuan dalam percobaan disusun dalam Rancangan Kelompok yang terdiri atas lima perlakuan (4 taraf konsentrasi insektisida permetrin $(50 ; 100 ; 200 ; 250$ ppm) dan satu kontrol (tanpa aplikasi insektisida). Setiap perlakuan diulang sebanyak 4 kali (ulangan sebagai kelompok) sehingga jumlah total petak percobaan adalah 20 petak (80 pohon; 320 pelepah).

Untuk menduga populasi awal (0 hari), maka pengamatan ulat api telah dilakukan satu hari sebelum perlakuan. Aplikasi insektisida dilakukan dengan menyemprot seluruh permukaan pelepah daun dan tandan bunga jantan dengan menggunakan alat semprot punggung (knapsack sprayer) dengan kapasitas 15 liter. Banyaknya larutan (volume semprot) yang digunakan adalah 2 liter/pohon.

Pengamatan populasi ulat api yang masih hidup dilakukan pada 3, 7, 10, dan 14 hari setelah aplikasi (hsa). Efikasi insektisida yang diuji didasarkan pada penurunan populasi ulat api (selisih populasi pada hari pengamatan dengan populasi awal). Sedangkan pengamatan kumbang penyerbuk E. kamerunicus dilakukan hanya satu kali yaitu pada hari ke-7 setelah aplikasi dengan cara memotong tandan bunga jantan dan memasukkannya ke kantung plastik untuk diamati dan dihitung di laboratorium. Data pengamatan selanjutnya dianalisis dengan sidik ragam yang dilanjutkan dengan uji perbandingan nilai tengah (Duncan's Multiple Range Test = Duncan's MRT) dengan menggunakan perangkat pengolah data SAS (SAS Institute Inc., 1988).

\section{HASIL DAN PEMBAHASAN}

\section{Dampak insektisida terhadap populasi Thosea sp.}

Hasil pendugaan populasi awal (0 hari, pengamatan satu hari sebelum aplikasi insektisida) menunjukkan bahwa populasi ulat api (Thosea sp.) pada tanaman kelapa sawit di seluruh petak percobaan relatif merata dengan kisaran kepadatan populasi 10,15 hingga 14,18 larva per pelepah. Hal ini dipertegas oleh hasil uji sidik ragam dan perbandingan nilai tengah pada populasi ulat api yang menunjukkan bahwa semua perlakuan termasuk kontrol tidak berbeda nyata satu sama lain (nilai $\mathrm{F}=1,40$ dan nilai $\mathrm{P}=0,2785$; Tabel 1). Dengan demikian dapat diasumsikan bahwa perbedaan populasi ulat api pada semua petak percobaan yang tercatat setelah aplikasi insektisida merupakan akibat dari pengaruh perlakuan insektisida permetrin.

Hasil pengamatan pada 3 hsa menunjukkan bahwa populasi ulat api pada semua perlakuan insektisida permetrin telah menurun dan hanya berkisar antara 0,05 hingga 2,00 larva/pelepah, sedangkan pada kontrol juga terjadi penurunan populasi menjadi 5,203 larva/pelepah. Namun, populasi ulat pada kontrol tersebut tetap nyata lebih tinggi dibandingkan dengan semua perlakuan. Dengan kata lain, hasil pengamatan pada periode ini menunjukkan bahwa perlakuan konsentrasi terendahpun (50 ppm) nyata lebih rendah dibandingkan dengan kontrol (tanpa insektisida). Hal ini menunjukkan bahwa insektisida permetrin 
Tabel 1. Rata-rata populasi hama ulat api (Thosea sp.) pada tanaman kelapa sawit yang telah disemprot dengan beberapa konsentrasi insektisida permetrin

\begin{tabular}{lccccc}
\hline $\begin{array}{l}\text { Perlakuan } \\
\text { (konsentrasi } \\
\text { permetrin) }\end{array}$ & \multicolumn{5}{c}{ Populasi ulat api (larva/pelepah) pada hari ke: } \\
\cline { 2 - 6 } & 0 & 3 & 7 & 10 & 14 \\
\hline Kontrol & $13,90 \mathrm{a}$ & $5,20 \mathrm{a}$ & $3,55 \mathrm{a}$ & $2,50 \mathrm{a}$ & $2,91 \mathrm{a}$ \\
$50 \mathrm{ppm}$ & $12,23 \mathrm{a}$ & $2,00 \mathrm{~b}$ & $0,00 \mathrm{~b}$ & $0,00 \mathrm{~b}$ & $0,00 \mathrm{~b}$ \\
$100 \mathrm{ppm}$ & $14,18 \mathrm{a}$ & $0,53 \mathrm{~b}$ & $0,08 \mathrm{~b}$ & $0,00 \mathrm{~b}$ & $0,00 \mathrm{~b}$ \\
$200 \mathrm{ppm}$ & $10,15 \mathrm{a}$ & $0,25 \mathrm{~b}$ & $0,00 \mathrm{~b}$ & $0,00 \mathrm{~b}$ & $0,00 \mathrm{~b}$ \\
$250 \mathrm{ppm}$ & $12,75 \mathrm{a}$ & $0,05 \mathrm{~b}$ & $0,00 \mathrm{~b}$ & $0,00 \mathrm{~b}$ & $0,00 \mathrm{~b}$ \\
\hline Nilai F & 1,40 & $5,96^{* *}$ & $8,99^{* *}$ & $3,31^{*}$ & $4,60^{* *}$ \\
Nilai P & 0,2785 & 0,0032 & 0,0004 & 0,0327 & 0,0096 \\
Duncan's MRT & 4,154 & 2,385 & 1,451 & 1,693 & 1,709 \\
\hline
\end{tabular}

Keterangan: Nilai tengah pada satu lajur yang diikuti oleh huruf yang sama tidak berbeda berdasarkan Duncan's Multiple Range Test . * Pengaruh perlakuan berbeda nyata.;

${ }^{* *}$ Pengaruh perlakuan berbeda sangat nyata.

dalam kondisi lapangan dapat menekan populasi ulat api.

Secara umum, hasil penelitian menunjukkan bahwa insektisida permetrin secara konsisten dapat menurunkan populasi ulat api. Hal ini menunjukkan bahwa semua perlakuan insektisida permetrin pada tanaman kelapa sawit berumur 4 tahun dapat menurunkan populasi ulat api secara nyata dibandingkan dengan kontrol untuk semua hari pengamatan. Sampai akhir pengamatan (14 hsa), semua ulat api pada perlakuan, kecuali kontrol telah mati (populasi 0 larva/pelepah). Hasil ini membuktikan bahwa daya bunuh insektisida permetrin masih efektif mengendalikan hama ulat api pada 14 hsa.

Untuk membuktikan lebih lanjut bahwa insektisida yang diuji benar-benar dapat menekan populasi ulat api, maka penurunan tingkat populasi ulat api (selisih populasi pada hari pengamatan dengan populasi awal) telah dihitung kemudian dianalisis dengan sidik ragam dan perbandingan nilai tengah. Hasil penghitungan menunjukkan bahwa penurunan populasi ulat api nyata lebih tinggi pada tanaman perlakuan dibanding dengan tanaman kontrol. Data pada periode 3 hsa menunjukkan penurunan populasi ulat api yang nyata $(83.65 \%$-99,60\%) terjadi pada tanaman kelapa sawit yang telah disemprot dengan insektisida permetrin dibandingkan dengan kontrol (nilai $\mathrm{F}=3,59$ dan nilai $\mathrm{P}=0,0246$; Tabel 2). Walaupun terjadi penurunan populasi ulat api pada tanaman kontrol sebesar 57.61\%, namun penurunan ini nyata lebih rendah dibandingkan dengan semua tanaman perlakuan (Tabel 2). Adanya penurunan populasi ulat api pada tanaman kontrol kemungkinan disebabkan sebagian larva yang masih bertahan hidup berubah menjadi pupa yang keberadaannya ada di dalam tanah.

Secara umum, hasil penelitian pada akhir pengamatan menunjukan bahwa penurunan populasi sebesar $100 \%$ terjadi pada semua perlakuan permetrin kecuali kontrol yang hanya mencapai 75,38\%. Namun hasil uji nilai tengah pada data ini tetap menunjukkan bahwa penurunan populasi pada semua perlakuan nyata lebih tinggi dibandingkan dengan kontrol (Tabel 2). Hal ini mempertegas hasil pengamatan bahwa telah terjadi penurunan populasi ulat api yang signifikan pada tanaman kelapa sawit yang disemprot dengan insektisida permetrin.

\section{Dampak Aplikasi Insektisida terhadap Serangga Penyerbuk (E. kamerunicus)}

Hasil pengamatan menunjukkan bahwa populasi serangga penyerbuk E. kamerunicus pada bunga jantan yang disemprot dengan konsentrasi permetrin terendahpun 50 ppm (209,0 kumbang per 
Tabel 2. Persentase penurunan populasi hama ulat api (Thosea sp.) pada tanaman kelapa sawit yang telah disemprot dengan beberapa konsentrasi insektisida permetrin

\begin{tabular}{llrrr}
\hline \multirow{2}{*}{$\begin{array}{l}\text { Perlakuan } \\
\text { konsentrasi }\end{array}$} & \multicolumn{4}{c}{ Persentase penurunan populasi pada hari ke: } \\
\cline { 2 - 5 } permetrin) & \multicolumn{1}{c}{3} & \multicolumn{1}{c}{7} & \multicolumn{1}{c}{10} & 14 \\
\hline Kontrol & $57,61 \mathrm{~b}$ & $73,27 \mathrm{~b}$ & $78,69 \mathrm{~b}$ & $75,38 \mathrm{~b}$ \\
$50 \mathrm{ppm}$ & $83,65 \mathrm{a}$ & $100,00 \mathrm{a}$ & $100,00 \mathrm{a}$ & $100,00 \mathrm{a}$ \\
$100 \mathrm{ppm}$ & $96,26 \mathrm{a}$ & $99,27 \mathrm{a}$ & $100,00 \mathrm{a}$ & $100,00 \mathrm{a}$ \\
$200 \mathrm{ppm}$ & $97,54 \mathrm{a}$ & $100,00 \mathrm{a}$ & $100,00 \mathrm{a}$ & $100,00 \mathrm{a}$ \\
$250 \mathrm{ppm}$ & $89,60 \mathrm{a}$ & $100,00 \mathrm{a}$ & $100,00 \mathrm{a}$ & $100,00 \mathrm{a}$ \\
\hline Nilai F & $3,59^{*}$ & $7,71^{* *}$ & $2,32^{*}$ & $3,04^{*}$ \\
Nilai P & 0,0246 & 0,0009 & 0,0952 & 0,043 \\
Duncan's MRT & 25,08 & 11,79 & 17,23 & 1,709 \\
\hline
\end{tabular}

Keterangan: Nilai tengah pada satu lajur yang diikuti oleh huruf yang sama tidak berbeda berdasarkan Duncan's Multiple Range Test . ${ }^{*}$ Pengaruh perlakuan berbeda nyata.;

${ }^{* *}$ Pengaruh perlakuan berbeda sangat nyata.

Tabel 3. Persentase populasi serangga penyerbuk E. kamerunicus, tanaman kelapa sawit yang telah disemprot dengan beberapa konsentrasi insektisida permetrin.

\begin{tabular}{lc}
\hline $\begin{array}{l}\text { Perlakuan } \\
\text { (konsentrasi permetrin) }\end{array}$ & $\begin{array}{c}\text { Populasi E. kamerunicus } \\
\text { (kumbang/tandan) }\end{array}$ \\
\hline Kontrol & $976,0 \mathrm{a}$ \\
$50 \mathrm{ppm}$ & $209,5 \mathrm{~b}$ \\
$100 \mathrm{ppm}$ & $77,5 \mathrm{~b}$ \\
$200 \mathrm{ppm}$ & $59,3 \mathrm{~b}$ \\
$250 \mathrm{ppm}$ & $12,5 \mathrm{~b}$ \\
\hline Nilai F & $18,27^{* *}$ \\
Nilai P & 0,0001 \\
Duncan's MRT & 244,2 \\
\hline
\end{tabular}

Keterangan: Nilai tengah pada satu lajur yang diikuti oleh huruf yang sama tidak berbeda berdasarkan uji DMRT; ** Pengaruh perlakuan berbeda sangat nyata.

tandan) nyata lebih rendah dibandingkan dengan kontrol (976,0 kumbang/tandan). Populasi penyerbuk yang terendah (12,5 kumbang/tandan) ditemukan pada perlakuan konsentrasi insektisida permetrin tertinggi (250 ppm), namun perbedaan populasi tersebut di antara perlakuan tersebut tidak nyata (Tabel 3). Hal ini memberi indikasi bahwa penyemprotan permetrin pada tanaman kelapa sawit mempunyai dampak buruk terhadap kumbang penyerbuk yang justru dibutuhkan dalam proses penyerbukan dan pembuahan kelapa sawit.

\section{SIMPULAN}

Dari penelitian lapangan pada tanaman kelapa sawit yang berumur 4 tahun menunjukkan bahwa penyemprotan insektisida permetrin pada agroekosistem kelapa sawit dapat menurunkan populasi ulat api (Thosea sp.) hingga 100\%. Namun, insektisida permetrin tidak hanya membunuh ulat api tetapi juga dapat mereduksi populasi kumbang penyerbuk utama kelapa sawit (E. kamerunicus). Populasi serangga penyerbuk ini turun secara drastis dari 976,0 ekor/tandan pada kontrol menjadi 12,5 ekor/tandan pada pohon yang telah disemprot dengan permetrin konsentrasi 250 ppm. Oleh karena itu, penggunaan insektisida permetrin pada agroekosistem tanaman kelapa sawit harus berhati-hati karena walaupun efektif mengendalikan hama utama, namun aplikasi insektisida tersebut mempunyai dampak buruk terhadap penyerbuk utama tanaman kelapa sawit yang bermanfaat pada proses pembuahan.

\section{SANWACANA}

Penulis mengucapkan terimakasih kepada Bapak Ir. Syarwani Arsyad selaku Sinder dan Bapak Makmur sebagai Mandor Besar Afdeling I perkebunan kelapa sawit PTPN VII Unit Usaha Bekri di Lampung Tengah, yang telah memberikan izin dan bantuan teknis dalam pelaksanaan penelitian ini. Ucapan terimakasih juga disampaikan kepada PT Probio atas dukungan dana. 


\section{DAFTAR PUSTAKA}

Badan Pusat Statistik. 2000. Lampung Dalam Angka. BPS Provinsi Lampung

Kalshoven, L.G.E. 1981. The Pests of Crops in Indonesia. (Rev. \& Trans.by: P.A. van der Laan \& G.H.L. Rotschild). PT Ichtiar Baru-Van Hoeve, Jakarta.

Risza, S. 1994. Kelapa Sawit: Upaya Peningkatan Produktivitas. Penerbit Kanisius, Yogyakarta.

Sipayung, A. 1987. Pengelolaan Hama Perkebunan Kelapa Sawit di Indonesia. Makalah dalam Lokakarya HIMAPI Medan, Indonesia.

SAS Institute Inc. 1988. SAS/STATA User's Guide. Release 6.03 Edition. Cary, NC.

Syed, R. 1986. Report on supply of Elaeidobious kamerunicus from low and high rainfall localities of Camerun to Costa Rica for United
Fruit Co. Oil Palm Operations. Harrisons Fleming Advisory Services Ltd.

Syed, R. \& A. Saleh.1987. Population of Elaeidobious kamerunicus Faust in relation to fruit set. Proc. Int. Oil Palm/Palm Oil Conferences. (In Press). Kuala Lumpur, Malaysia .

Syed , R., J.H. Law \& R.H.W. Corley. 1982. Insect pollination of oil palm: introduction, establisment and pollinating efficiency of Elaeidobious kamerunicus. Malaysia Planter 58: 547-561.

Wahid, M.B.; Z. Masijan; A.H. Halim \& D. Mohid. 1987. The population census and the pollination efficiency of the weevil E. kamerunicus in Malaysia. A status report 1983-1986. Proc. Int. Oil Palm/Palm Oil Conferences (In Press). Kuala Lumpur, Malaysia.

Yee, C.B., K.C. Lim; E.C.Ong, \& K.W. Chan. 1985. The effect of Elaeidobious kamerunicus Faust on bunch components of $E$. guineensis. In Wokrsp. Proc. Palm Oil Res. Inst. Malaysia. No. 8: 129-139. 
Hasibuan et al.: Dampak insektisida permetrin terhadap serangga hama dan serangga penyerbuk kelapa sawit 
J. Hama dan Penyakit Tumbuhan Tropika 2(2), 2002 